Binninger M., Dlouhy J., Oprach S., and Haghsheno S. (2017). "Learning Simulation Game for Takt

Planning and Takt Control” In: LC3 2017 Volume II - Proceedings of the 25th Annual Conference of the International Group for Lean Construction (IGLC), Walsh, K., Sacks, R., Brilakis, I. (eds.), Heraklion,

Greece, pp. 227-233. DOI: https://doi.org/10.24928/2017/0088

\title{
LEARNING SIMULATION GAME FOR TAKT PLANNING AND TAKT CONTROL
}

\author{
Marco Binninger ${ }^{1}$, Janosch Dlouhy ${ }^{2}$, Svenja Oprach ${ }^{3}$, and Shervin Haghsheno ${ }^{4}$
}

\begin{abstract}
The methods of Takt Planning and Control are applied in many companies. When conducting trainings with employees, subcontractors and clients the topic of Lean Construction is often imparted. The difficulty often lies in teaching abstract concepts to participants in a way that is clear and that reflects reality. A simulation game supports teaching, by its simplified description of real processes and helps transfer the method into practice. A good example is the Villego $^{\mathrm{TM}}$ simulation game for the use of the Last Planner System. At Karlsruhe Institute of Technology (KIT) a learning simulation game comprising three rounds was developed. Presenting Takt Planning and Control in a production facility, it includes a scale model of a real project. In addition to tasks for the construction manager and various trades, roles for the client, health and safety manager and quality manager were integrated. This article describes the development, the game instructions and the empirical evaluation of the benefits in using Lean in the simulation game. It has been successfully tested multiple times and implemented for training by a number of companies. It offers the potential to make the method of Takt Planning and Takt Control more accessible and easier to understand.
\end{abstract}

Keywords: Learning Simulation Game, Lean Game, Takt Planning, Takt Control.

\section{INTRODUCTION}

Trainings based on pure theory assume the approach that "knowledge is a result of learning facts and routines" (Mandl et al. 2015, p.65). Modern approaches toward learning focus on reflective skills and needs-based learning through a combination of theory and practice (Pellicer and Ponz-Tienda, 2014). The knowledge learned in simulation games can be used to actively test the theory in a simplified form. Examples of well-known simulation games for the construction industry include the Villego ${ }^{\mathrm{TM}}$ simulation game developed for the Last-Planner System (Villego). Other examples include the game Parade of Trades (Tommelein et al. 1998), which shows variance between parameters together with system effectiveness and the game for Location-Based Management System from Seppänen (2012). These games have been documented and analysed in academia.

Some games and trainings in the field of Takt Planning and Takt Control have been developed by consultancies or by companies internally. According to the research of the authors there has been little scholarly documentation or analysis of trainings of this

Research Fellow, Karlsruher Institute of Technology, Germany, marco.binninger@kit.edu

Research Fellow, Karlsruher Institute of Technology, Germany, janosch.dlouhy@kit.edu

Team Lean Construction, BMW AG, Germany, svenja.oprach@bmw.de

Professor, Karlsruher Institute of Technology, Germany, shervin.haghsheno@kit.edu 
nature. Also according to Hirota and Formoso (1998) it is not trivial to incorporate Lean Construction principles and approaches in trainings in an understanding way and so that old thinking patterns, even of professionals, can be abandoned.

Within the framework of research at the Karlsruhe Institute for Technology (KIT) a training concept for the topic area of Takt Planning and Takt Control was developed. A simulation game based on a real project in the industrial sector supports the development of learning content.

\section{GoAl of THE TRAINING}

In the modern (working) world, it is generally no longer sufficient to rely upon a single set of knowledge and skills learnt in the past (Kriz 2006). There is a demand for the ability to self-organise and make decisions to solve open problems (Erpenbeck und Rosenstiel 2003). For this reason, there is a need to develop understanding and a basis for being able to respond according to any given situation at a later date.

The primary goals of the training are providing a foundation in the methods of Takt Planning and Takt Control and an application based on the 'Three Level Model' (Dlouhy et al. 2016). The secondary goal is to develop an understanding of Lean principles. The Lean values should be known and participants should have a basic feeling for value creation and waste. A simulation game plays a important role and can be beneficial to implementing these Lean principles (Heyl 2015, Choomlucksana 2013). Soft factors such as team building, commitment, value to the client, communication and collaboration are also taught.

The implementation of the simulation game helps to reduce skepticism regarding transferability of Lean principles to construction projects. If a participant does not begin with this openness, the effectiveness of learning and absorption of knowledge remain low.

\section{DeVelopment of the Simulation Game}

The development of the simulation game was oriented toward the five levels of reality according to Kriz (2003). Based on the real world, these are applicable from the design of the simulation game to its execution, debriefing, meta-debriefing and evaluation.

- Real World: The first level of reality reflects the real world, a relevant piece of which has been selected for the simulation game.

- Design phase: During the design phase this real world is transferred to a model. Here through conscious or subconscious reduction of complexity, reality may be distorted. This results in a second level of reality. The design phase ends with a construction of a prototype, which should be tested to be reviewed and modified.

- Execution of the simulation game results in a simulated reality - the third level of reality. The participants operate within the second level of reality provided by the simulation model, but are influenced by their knowledge and experience from the real world - the first level of reality - which they recognise during the simulation game.

- The debriefing allows for the transfer of the resultant simulation game reality back to the real world. The fourth level of reality is derived by comparing the first and third level of reality. 


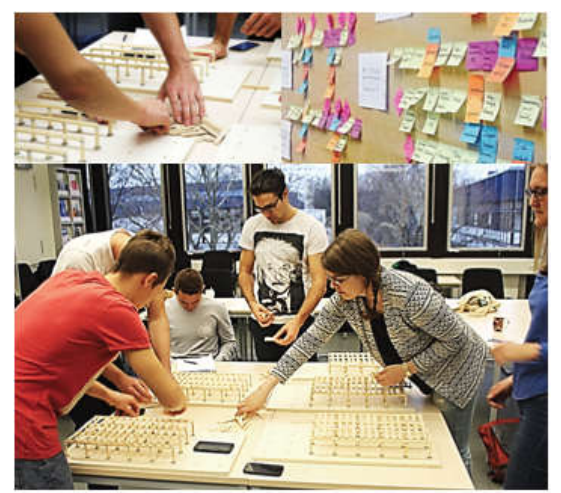

- Meta-debriefing and evaluation together form the fifth level of reality in which all levels of reality are compared with one another. It is checked whether the results of the debriefing match the set learning goals.

The basis for the real world was an industrial project executed using Lean Construction principles. The project is described in a paper by Dlouhy et al. (2016), but will not be discussed further in this contribution. From the entire project a simplified subpart was selected for development of the simulation game. Through the input of reliable real values, the learning game gains increased credibility and acceptance from participants.

To make carrying over of the effects of the simulation game easier, the system elements were adapted to a wooden element model with as much detail as possible. Beginning with foundation piles, over the various loadbearing systems up to the ceiling coverings, drainage and building envelope, the building was reconstructed to a manageable scale. Figure 1 shows a comparison of the actual drainage piping to its adaptation in the model.

Reality: Drainage/Pipeline

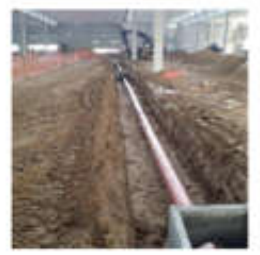

Model: Drinking Straw

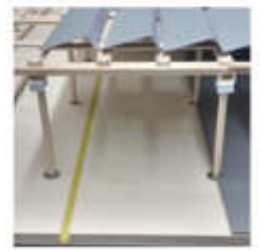

Figure 1: Comparison of reality and model

To support the carrying out of the simulation game an instructional presentation, guidelines for all participants and an Excel workbook were developed.

Individual processes as well as the entire simulation game were tested and compared on multiple occasions within the Lean research team at the Karlsruhe Institute for Technology. Figure 2 shows a trial round during the development phase. At the end of the design phase, a wooden prototype was converted into a 3D printed model, and a best practice procedure was determined.

Figure 2: Test round during development using the prototype

During the debriefing after each game round the following questions were placed in accordance with Kriz et al. (2002). 
- How did you feel?

- What happened?

- What did you learn?

- What do the game and reality have in common?

- What would have happened if...?

- How will it continue?

After the conception of a design step and the test rounds in teams, a meta-debriefing was carried out with the participants. For this a special questionnaire was developed. The results of these are evaluated in chapter 5 .

\section{CARRYING OUT OF THE SIMULATION GAME}

The training concept is designed as a day seminar for a group of 12-20 participants. Figure 3 shows on the left side the composition of the roles and the problems applicable for each is described.

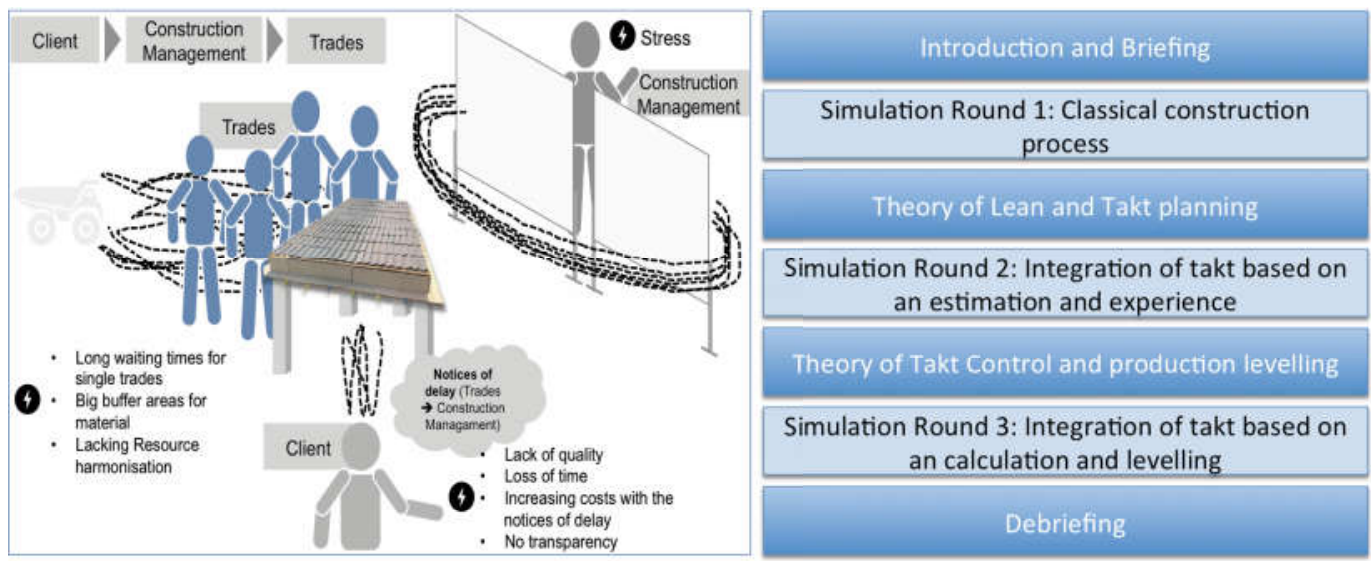

Figure 3: Roles, Structure and effects of the training

The training provides a core simulation game, which has the flexibility to be expanded upon in different ways. This means that the group is not separated into smaller subgroups, but rather the entire training day is focused on one simulation game. The training includes three game rounds. Lean principles are taught through two theoretical, and three simulation game lessons. Every game round has a duration of 15 minutes. The execution of the simulation game and the development of the roles of the participants are described below. The structure of the training is shown in figure 3 on the right side.

After the welcoming, introduction, asking of goals and expectations as well as a short briefing the first round begins. The roles (10 trades, construction manager, client and health and safety manager) are allocated. The trades have 10 minutes to plan the work, familiarise themselves with the drawings and become familiar with the building material. The construction manager uses this time to prepare a project schedule. After this time the simulation game begins. The construction manager organises the trades according to his or her timeline and attempts to manage the construction site. After only a few minutes the construction manager loses control, and the characteristic chaos of the 'classic' construction approach becomes apparent. If the execution process is disrupted, the trades are allowed to issue a notice of delay. After 15 minutes the clock is stopped, 
and the status of completion is recorded. Only isolated parts of the building are finished. Additionally, the participants are asked for their impressions and knowledge gained.

In connection to round 1 of the game a lesson is given on the content of Lean Construction. It is attempted to incorporate the Lean principles of flow and pull by determining the sequence of works (process analysis). In addition, a Takt time is estimated, and an attempt is made to introduce the zero defects principle in the form of short-cycled inspections.

Building on the theory, the information learned in the first part are integrated within the second round. The construction manager again has some minutes to develop a construction strategy. The build-up and execution of the simulation game is the same, but the trades move through the building systematically according to the execution plan developed, and attempt to keep to the predetermined Takt. However, after some minutes the contractors no longer keep to the Takt, and from the perspective of the construction manager the level of control is as chaotic as in the first round. There is no time for shortcycled inspections as the construction manager is occupied with solving problems. In this round, large parts of the building are completed, which still often do not fulfil the prioritisation of the client.

In the second theory session, which follows, the topic of improved control is explored in greater detail and instruments such as a Takt Control board or a Takted production plan are introduced. The duration of individual trades is analysed and the level of effort determined. With the help of these tools the works are Takted (Haghsheno et al., 2016). The bottlenecks in production are eliminated to allow for an optimised flow.

Round 3 is carried out in the same way, but the site is managed with the help of a regular, short-cycle Takt Control board. After some minutes the focus of the construction manager shifts from reactive coordination to a proactive and anticipative approach. This also allows space to develop improvements in quality. In this round the building is usually fully completed ahead of schedule.

\section{EMPIRICAL AND QUALITATIVE ASSESSMENT}

More than 100 participants over 15 trainings were surveyed for feedback. The participants included both German and foreign project managers, architects, general contractors, subcontractors, technical specialists, designers and project controllers. The questionnaire was divided into two parts with 15-20 closed questions in each. The first and second parts of the questionnaire were filled out at the start and beginning of the training respectively.

The majority of the participants in the simulation game had long-term experience in the construction industry (56\% with more than 10 years, $26 \%$ with $5-10$ years and $18 \%$ with less than five years). Furthermore $77 \%$ had not yet gained any experience with Lean projects. Before completing the training only half $(54 \%)$ were convinced of the need to implement Lean Construction in their projects. $100 \%$ found physical simulation game helpful for delivering learning content.

The first part of the questionnaire asked participants for compare the importance of time, cost and quality. $80 \%$ believed that time had the highest priority in industrial projects. Cost was named as the next most significant factor, and quality the least important.

However, participants only gave a low to medium rating to their own knowledge of Takt Planning. Many were also often dissatisfied with the results of time planning, but were aware that their influence on time planning is significant. 
The relevance of keeping to a schedule shows that the focus of the game should be time planning. In particular, the evaluation of soft factors supports the use of Takt Planning and Takt Control in the simulation game: Area prioritisation, transparency, trust and process flexibility were rated as very important in comparison to product flexibility. Takt Planning and Takt Control support prioritisation of areas through defining Takt areas according to the client's priorities. Takt Planning enables a high level of transparency for all project stakeholders. The visualisation of the Takt Plan allows possible alternative processes to be quickly visible, which allow Takt Control a high degree of process flexibility. The trust of all project stakeholders is strengthened by the means of representation, collaboration and transparency.

In the second part of the questionnaire achieved learning outcomes were surveyed. The complexity of the simulation game was rated as appropriate by $67 \%$ of the participants surveyed. The 15-minute duration of the rounds was considered appropriate by $83 \%$. The balance between theory and practice was rated appropriate by $100 \%$. All participants also agreed the simulation game clearly or to some extent provide a real building project in simplified form. Surveying of client priorities was rated as clearly apparent by $83 \%$. On average there is a clear improvement in time planning between the three rounds. A comparison of rounds 1 and 2 show that in round 1 only $4-20 \%$ of simulations were fully completed, whereas in round 2 the percentage was $80-100 \%$. Further on from round 2 to round 3 the time of completion improve from about 15:00 to 12:00 minutes. Through an analytic and mathematical approach of the third round, the size of Takt areas and Takt time were reduced by two thirds. Through implementation of Takt Control the areas could reach close to $100 \%$ of the calculated potential. In every round completed there was a clearly measurable trend toward a reduction in time. In the debriefings after each round, soft Lean factors such as trust, stability, transparency and collaboration were recognised.

Table 1 shows the improvements by the pre-defined KPIs from round to round.

Table 1: Average key performance indicators (KPI) during the three simulation game rounds

\begin{tabular}{cccc}
\hline KPI & $\mathbf{1}^{\text {st }}$ round & $\mathbf{2}^{\text {nd }}$ round & $\mathbf{3}^{\text {rd }}$ round \\
\hline Deviation notices & 30 & 10 & 0 \\
Accidents & 4 & 1 & 0 \\
Level of completion & $4-20 \%$ & $80-100 \%$ & $100 \%$ \\
Completion time & $>15 \mathrm{~min}$ & $15 \mathrm{~min}$. & $12: 00 \mathrm{~min}$ \\
$\begin{array}{c}\text { Fulfilment of the } \\
\text { clients value }\end{array}$ & $0 \%$ & $50 \%$ & $100 \%$ \\
\hline
\end{tabular}

\section{CONCLUSION AND OUTLOOK}

The training and simulation game are a fixed part of a large property development organisation, which has implemented this system. This system has also been implemented as part of teaching at the Karlsruhe Institute of Technology. Preliminary enquiries have been made by further interested companies. Presently the training is focused on a small sub-process - construction of the shell for a production facility. 
Broadening of the simulation game to preceding process steps such as design, approvals or logistics as well as succeeding process steps such as fit-out is possible. Of the participants surveyed, $67 \%$ agree for the need to broaden the simulation game for fit-out and installation works. Additionally, $22 \%$ would like to see incorporation of the equipment installation process in production facilities, and $11 \%$ would also like to incorporate the deconstruction processes.

At present a continuation of the simulation game to include fit-out and installation works is being developed.

\section{REFERENCES}

Choomlucksana, J. (2013): A study of the impact of collaborative and simulation sessions on learning Lean principles and methods. PhD. Oregon State University USA.

Dlouhy, J. , Binninger, M. , Oprach, S. \& Haghsheno, S. 2016, 'Three-Level Method of Takt Planning and Takt Control - a New Approach for Designing Production Systems in Construction' In:, 24th Annual Conference of the International Group for Lean Construction. Boston, USA, 20-22 Jul 2016.

Erpenbeck, John; Rosenstiel, Lutz von (Hg.) (2003): Handbuch Kompetenzmessung. Erkennen, verstehen und bewerten von Kompetenzen in der betrieblichen, pädagogischen und psychologischen Praxis. Stuttgart: Schäffer-Poeschel. (Manual measuring skills. Recognise, understand and evaluate skills in occupational, educational and psychological practice)

Haghsheno, S. , Binninger, M. , Dlouhy, J. \& Sterlike, S. 2016, 'History and Theoretical Foundations of Takt Planning and Takt Control' In:, 24th Annual Conference of the International Group for Lean Construction. Boston, USA, 20-22 Jul 2016.

Heyl, J.V. 2015, 'Lean Simulation in Road Construction: Teaching of Basic Lean Principles' In:, Seppänen, O., González, V.A. \& Arroyo, P., 23rd Annual Conference of the International Group for Lean Construction. Perth, Australia, 29-31 Jul 2015. pp 403-412.

Hirota, E.H. \& Formoso, C.T. 1998, 'Some Directions for Developing Construction Management Training Programmes on Lean Construction' In:, 6th Annual Conference of the International Group for Lean Construction. Guarujá, Brazil, 13-15 Aug 1998.

Kriz, Willy C. (2003): Creating Effective Interactive Learning Environments through Gaming Simulation Design. In: Journal of Simulation \& Gaming 34 (4), p. 117-134.

Kriz, Willy C. (2006): Systemkompetenz als Zieldimensionkomplexer Simulationen. (System competence as target dimension of complex simulations) In: bwp@ Berufs und Wirtschaftspädagogik - online (10). Online available at http://www.bwpat.de/ausgabe10/land_siemon_bwpat10.pdf.

Kriz, Willy C.; Nöbauer, Brigitta (2002): Teamkompetenz. Konzepte, Trainingsmethoden, Praxis (Team competence. concepts, training methods, practice). Göttingen: Vandenhoeck \& Ruprecht. Online available at http://www.socialnet.de/rezensionen/isbn.php?isbn=978-3-525-46162-4.

Mandl, Heinz; Geier, Boris; Hense, Jan (2015): Planspiele und Serious Games -Basis einer neuen Lernkultur. Aufl. Bonn, Bielefeld: Bundesinst. für Berufsbildung; Bertelsmann, p. 65-70. (Simulations and Serious Games as basis of a new learning culture.)

Pellicer, E. \& Ponz-Tienda, J.L. 2014, 'Teaching and Learning Lean Construction in Spain: A Pioneer Experience' In:, Kalsaas, B.T., Koskela, L. \& Saurin, T.A., 22nd Annual 
Conference of the International Group for Lean Construction. Oslo, Norway, 25-27 Jun 2014. pp 1245-1256

Seppänen, O. 2012, 'A Production Control Game for Teaching of Location-Based Management System's Controlling Methods' In:, Tommelein, I.D. \& Pasquire, C.L., 20th Annual Conference of the International Group for Lean Construction. San Diego, USA, 18-20 Jul 2012

Tommelein, I.D. , Riley, D. \& Howell, G.A. 1998, 'Parade Game: Impact of Work Flow Variability on Succeeding Trade Performance' In:, 6th Annual Conference of the International Group for Lean Construction. Guarujá, Brazil, 13-15 Aug 1998.

Villego (n.d.). Villego - Last Planner Simulation. Www.villego.com Available at: [Accessed 06 Mar. 2017]. 